\title{
Spectroelectrochemical Characterization of Organic-Inorganic Materials Containing Porous Vanadium (V) Oxide, Poly-o-Methoxyaniline and Poly(Ethylene Oxide)
}

\author{
Bruno Leuzinger da Silva, Dane Tadeu Cestarolli, Elidia Maria Guerra* \\ Department of Chemistry, Biotechnology and Bioprocess Engineering, Federal University of São João Del Rei, \\ Ouro Branco, Brazil \\ Email: *elidiaguerra@ufsj.edu.br
}

How to cite this paper: da Silva, B.L., Cestarolli, D.T. and Guerra, E.M. (2019) Spectroelectrochemical Characterization of Organic-Inorganic Materials Containing Porous Vanadium (V) Oxide, Poly- $o$-Methoxyaniline and Poly(Ethylene Oxide). Journal of Materials Science and Chemical Engineering, 7, 12-23.

https://doi.org/10.4236/msce.2019.710002

Received: July 27, 2019

Accepted: October 18, 2019

Published: October 21, 2019

Copyright $\odot 2019$ by author(s) and Scientific Research Publishing Inc. This work is licensed under the Creative Commons Attribution International License (CC BY 4.0).

http://creativecommons.org/licenses/by/4.0/

\begin{abstract}
In this study, the synthesis and spectroelectrochemical analysis of hybrid materials containing poly- $o$-methoxyaniline/porous $\mathrm{V}_{2} \mathrm{O}_{5}$, poly(ethylene) oxide/ porous $\mathrm{V}_{2} \mathrm{O}_{5}$ and poly- $O$-methoxyaniline/poly(ethylene) oxide/porous $\mathrm{V}_{2} \mathrm{O}_{5}$, which have high potential for applications in batteries and electronics, is reported. The hybrid materials were obtained by intercalation of the polymers into the porous $\mathrm{V}_{2} \mathrm{O}_{5}$ matrix. These new compounds were characterized using $\mathrm{dc}$ conductivity, and, for spectroelectrochemical studies, ultraviolet visible (UV-vis) spectroscopy as well as cyclic voltammetry were used. The optical band gap values of the hybrid materials were estimated using Tauc plot. The introduction of organic materials into the inorganic species resulted in the reduction of $\mathrm{V}^{\mathrm{V}}$ ions to $\mathrm{V}^{\mathrm{IV}}$, increasing the dc conductivity and affecting the spectroelectrochemical properties of the samples.
\end{abstract}

\section{Keywords}

Porous $\mathrm{V}_{2} \mathrm{O}_{5}$, Polymers, Spectroelectrochemistry, dc Conductivity, Optical Band Gap

\section{Introduction}

Preparation and development of new hybrid materials, containing organic and inorganic structures, have been extensively studied as they introduce the possibility of composite chemical and physical properties that may not be present in the starting components alone [1] [2] [3] [4] [5]. The combination is made by the incorporation of one or more organic species into an inorganic matrix and it 
occurs mainly though weak interactions, such as van der Waals or electrostatic interactions [6]. In the literature, special emphasis has been placed on hybrid materials prepared from inorganic materials obtained by the sol-gel route followed by intercalation with an organic species [2] [5] [7]-[12]. The sol-gel route is a synthesis that involves the hydrolysis and condensation of metal alkoxides or hydroxylated precursors, followed by an inorganic polymerization reaction [13]. During intercalation reactions, theses precursors can be considered a matrix or host for organic molecules. Vanadium pentoxide $\left(\mathrm{V}_{2} \mathrm{O}_{5}\right)$ is an inorganic matrix that presents a lamellar structure and can be used as host material. The combination of $\mathrm{V}_{2} \mathrm{O}_{5}$ and an organic material yield new material called as hybrid material with improved properties known as synergic effects [14] [15]. Organic molecules are inserted into the inorganic layered structure and reduction of the oxide induces oxidation as well as polymerization of the organic molecules, resulting in a host-guest compound or hybrid material [1] [16] [17] [18]. Some polymers, such as poly(ethylene oxide), present a ionic conductivity that assist in improving of charge transfer during the electrochemical process. On the other hand, poly-o-methoxianiline is an electric conductivity and once intercalated into the matrix acts on increasing of total charge. The presence of a polymer species in the inorganic host can result in an improvement of the properties, such as electrochemical performance. However, in the solid state, the kinetics of ion insertion/de-insertion during the electrochemical process can be affected, if the hybrid material has a low surface area. To overcome this disadvantage, the surface area can be increased though the use of a highly porous network produced by mesoporous synthesis, which consequently reduces the length of the diffusion path and improves the kinetic performance [19]. Additionally, some hybrid materials undergo a color change during the electrochemical process [20] [21] [22]. This effect can be studied through spectroelectrochemical monitoring of the electrode processes during the redox process [23]. Furthermore, using Tauc's method, it is possible to evaluate the optical absorption of materials. This method is often used to calculate the band gap from results of spectral absorption, which are fitted using a power-law expression. To calculate the band gap, the quantity $\alpha h v^{1 / r}$ (Equation (1)) is plotted against the photon energy. The band gap is determined from the $\mathrm{x}$-intercept of the linear portion of the Tauc plot. Additionally, the fitted exponent indicates either a direct or indirect electron transition [24]

$$
\alpha h v^{1 / r}=B(h v-E g)
$$

In Equation (1), $\alpha$ is the absorption coefficient, $h$ is Planck's constant, $v$ is the photon frequency, $E g$ is the band gap, and $B$ is the slope of the linear portion of the Tauc plot. The value of $r$ depends on the nature of electronic transition:

$$
\begin{aligned}
& \text { direct allowed transition } r=1 / 2 \text {; } \\
& \text { indirect allowed transition } r=2 \text {; } \\
& \text { direct forbidden transition } r=3 / 2 \text {; and }
\end{aligned}
$$


indirect forbidden transition $r=3$.

Based on the literature [25], an exponent of $1 / r=3 / 2$ has been reported for vanadium pentoxide films, suggesting direct, forbidden transitions. To the best of our knowledge, there are few reports of the synthesis, or morphological, electrical, electrochemical, or optical studies of mesoporous $\mathrm{V}_{2} \mathrm{O}_{5}$ /polymer hybrid materials [7] [8] [26]. In this context, our interest is to investigate the conductivity and spectroelectrochemical properties of materials produced through intercalation of poly(ethylene oxide) (PEO) and poly-o-methoxyaniline (POMA) into the interlayer space of porous vanadium $(\mathrm{V})$ oxide (VOP); namely the host-guest hybrid materials VOP/PEO and VOP/POMA, respectively, and a ternary hybrid; mesostructured VOP/POMA/PEO.

\section{Experimental}

\subsection{Materials}

All chemical reagents were used as received, unless otherwise specified. Poly (ethylene oxide), PEO (average molecular weight 100,000 g. mol ${ }^{-1}$ ) was acquired from AcrosOrganics. Acetonitrile (chromatographic grade) was obtained from Fluka. Vanadium $(\mathrm{V})$ oxide powder and the monomer $o$-methoxyaniline were purchased from Sigma-Aldrich.

\subsection{Synthesis of Porous Vanadium(V) Oxide}

Vanadium(V) oxide powder was dissolved in $0.1 \mathrm{~mol} \cdot \mathrm{L}^{-1}$ aqueous sodium hydroxide, with stirring, for $24 \mathrm{~h}$, at $50^{\circ} \mathrm{C}$. Subsequently, this solution was combined with an aqueous mixture containing the surfactants cetyltrimethylammonium bromide (CTAB)/hexadecylamine (HDA) at $0.01 \mathrm{~mol} \cdot \mathrm{L}^{-1}(1: 1)$, and aqueous magnesium chloride at $0.003 \mathrm{~mol} \cdot \mathrm{L}^{-1}$ and $\mathrm{pH}=3$. The resulting mixture was stirred at $25^{\circ} \mathrm{C}$, for $24 \mathrm{~h}$, followed by aging at room temperature for 7 days. Subsequently, the resulting brown solid was washed with distilled water until reaching neutral $\mathrm{pH}$, and dried at $60^{\circ} \mathrm{C}$, for $24 \mathrm{~h}$. This mixture (MS) had a molar composition of 1.0:0.03:0.1 ( $\mathrm{V}_{2} \mathrm{O}_{5}: \mathrm{MgCl}_{2}$ :surfactants). Then, a black porous material was obtained from MS by removal of the surfactant molecules via thermal treatment (above $350^{\circ} \mathrm{C}$ ), which afforded the final material, designated VOP. VOP had a molar composition of $1.0 \mathrm{~V}_{2} \mathrm{O}_{5} / 0.03 \mathrm{MgCl}_{2}$.

\subsection{Synthesis of the VOP/Polymer Hybrid Materials}

The $o$-methoxyaniline monomer was purified by vacuum distillation before use. The hybrid material based on poly-o-methoxyaniline (POMA) and VOP was prepared by adding VOP $\left(2.2 \times 10^{-3} \mathrm{~mol} \cdot \mathrm{L}^{-1}\right)$ to $o$-methoxyaniline $\left(8.8 \times 10^{-3}\right.$ mol. $\mathrm{L}^{-1}$ ) both aqueous solution. The combination was stirred for $48 \mathrm{~h}$ resulting in the binary material VOP/POMA. To prepare the hybrid material based on PEO and VOP, PEO $\left(160 \times 10^{-7} \mathrm{~mol} \cdot \mathrm{L}^{-1}\right)$ was added to VOP $\left(1.37 \times 10^{-3} \mathrm{~mol} \cdot \mathrm{L}^{-1}\right)$ in aqueous solution, and the mixture was stirred for $48 \mathrm{~h}$, leading to another binary material, VOP/PEO. Finally, the dark green composite containing both po- 
lymers (ternary material) was prepared by adding VOP/PEO $(0.50 \mathrm{~mL})$ to $o$-methoxyaniline $(0.1 \mathrm{~mL})$, with stirring, for $48 \mathrm{~h}$ at room temperature, affording VOP/POMA/PEO.

\subsection{Equipment and Procedure}

The dc conductivity was measured against temperature in the 150 - $350 \mathrm{~K}$ range. The measurements were performed in an evacuated chamber using a dc bias of 1 $\mathrm{V}$ between silver electrodes. The ultraviolet visible (UV-vis) spectral measurements were recorded on a spectrophotometer (Varian Cary 50) with the hybrid materials onto an indium tin oxide (ITO) electrode. Cyclic voltammetry experiments were carried out with an Eco Chemie AUTOLAB model PGSTAT30 (GPES/FRA) potentiostat/galvanostat interfaced with a computer. A conventional three-electrode arrangement was used, consisting of an ITO working electrode, a platinum wire auxiliary electrode and a saturated calomel (SCE) reference electrode in $0.1 \mathrm{~mol} \cdot \mathrm{L}^{-1} \mathrm{LiClO}_{4}$ in acetonitrile, at a scan rate of $v=20$ $\mathrm{mV} \cdot \mathrm{s}^{-1}$. The hybrid materials were deposited on the working electrode surface by evaporating $4 \mu \mathrm{L}$ at room temperature. The experiments were carried out in an inert atmosphere by bubbling $\mathrm{N}_{2}$ through the solution at room temperature. For the spectroelectrochemical experiments, the potentiostat/galvanostat was coupled with the spectrophotometer, and a three-electrode system was assembled in a quartz cell with a $1.00 \mathrm{~cm}$ optical path length. An ITO electrode was employed as the working electrode in the presence of a SCE reference electrode, the auxiliary electrode was a platinum wire, and $0.1 \mathrm{~mol} \cdot \mathrm{L}^{-1}$ of $\mathrm{LiClO}_{4}$ in acetonitrile was used as the supporting electrolyte.

The direct energy gap is calculated using UV-vis spectra and the Tauc Relation (Equation (1)). Additionally, frontier orbitals (HOMO and LUMO) were estimated using Equation (2) and Equation (3) [27]:

$$
\begin{gathered}
E_{\mathrm{HOMO}}=-\left(E_{\text {ox }}^{\text {onset }}+4.99\right) \\
E_{\mathrm{LUMO}}=E_{\text {НОмО }}+E_{\text {gap }}
\end{gathered}
$$

\section{Results and Discussion}

To analyze and compare the influence of interactions in the VOP/polymers on the conductivity phenomena after the intercalation reaction, the conductivity values of VOP/PEO, VOP/POMA, and VOP/POMA/PEO were evaluated (Figures 1-3). An increase in conductivity, compared with that of $\mathrm{V}_{2} \mathrm{O}_{5}$, occurred after the intercalation reaction, and had been previously reported by our group [22]. The conductivity values were $5.61 \times 10^{-3}, 5.03 \times 10^{-3}$, and $5.01 \times 10^{-3}$ $\left(\Omega \cdot \mathrm{cm}^{-1}\right)$ and the activation energies were $1.09,0.93$, and $1.05(\mathrm{eV})$, after introduction of PEO, POMA, and the combined polymers to the VOP structure, respectively. These results are quite similar considering that the structures of the polymers are different. The polymers have a linear structures and interact with VOP through van der Waals forces [28]. However, the variations in conductivity 


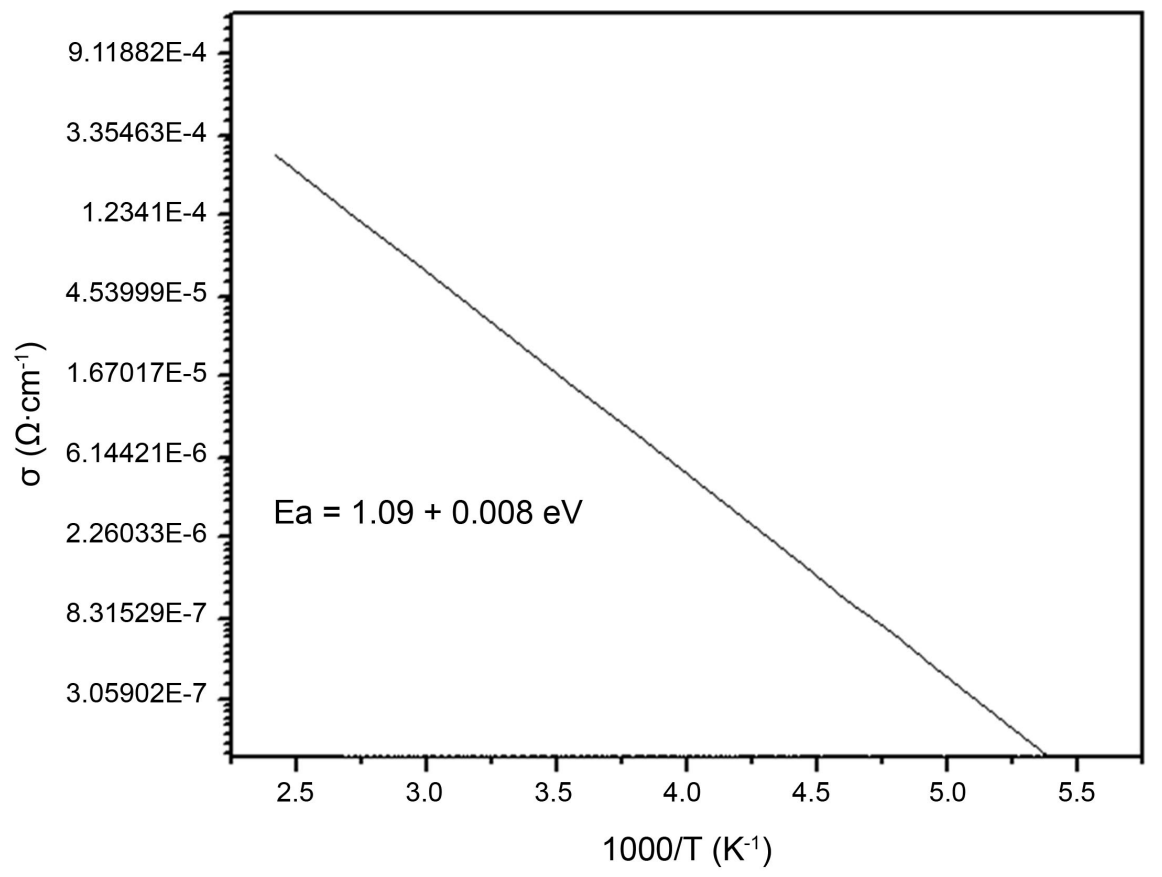

Figure 1. dc conductivity measurements of VOP/PEO.

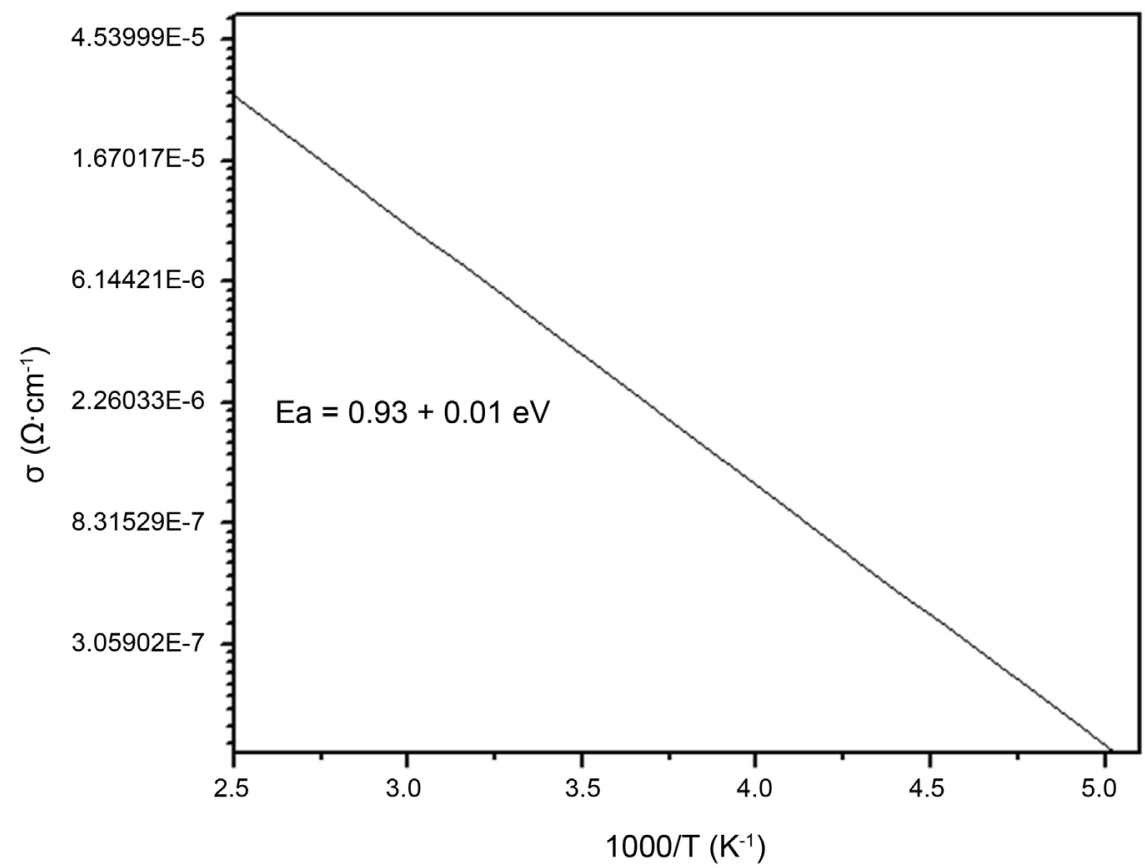

Figure 2. dc conductivity measurements of VOP/POMA.

can be attributed to the fact that PEO is an ionic conductor and POMA is an electronic conductor (polarons). In the literature, an increase in the $\mathrm{V}^{\mathrm{IV}} /\left(\mathrm{V}^{\mathrm{IV}}+\right.$ $\mathrm{V}^{\mathrm{V}}$ ) ratio of VOP is observed after intercalation of PEO [2]. So, it is possible to infer that the conductivity of these materials depends on the change in the oxidation state of VOP caused by PEO interaction and/or polaron transport along the POMA backbone. 


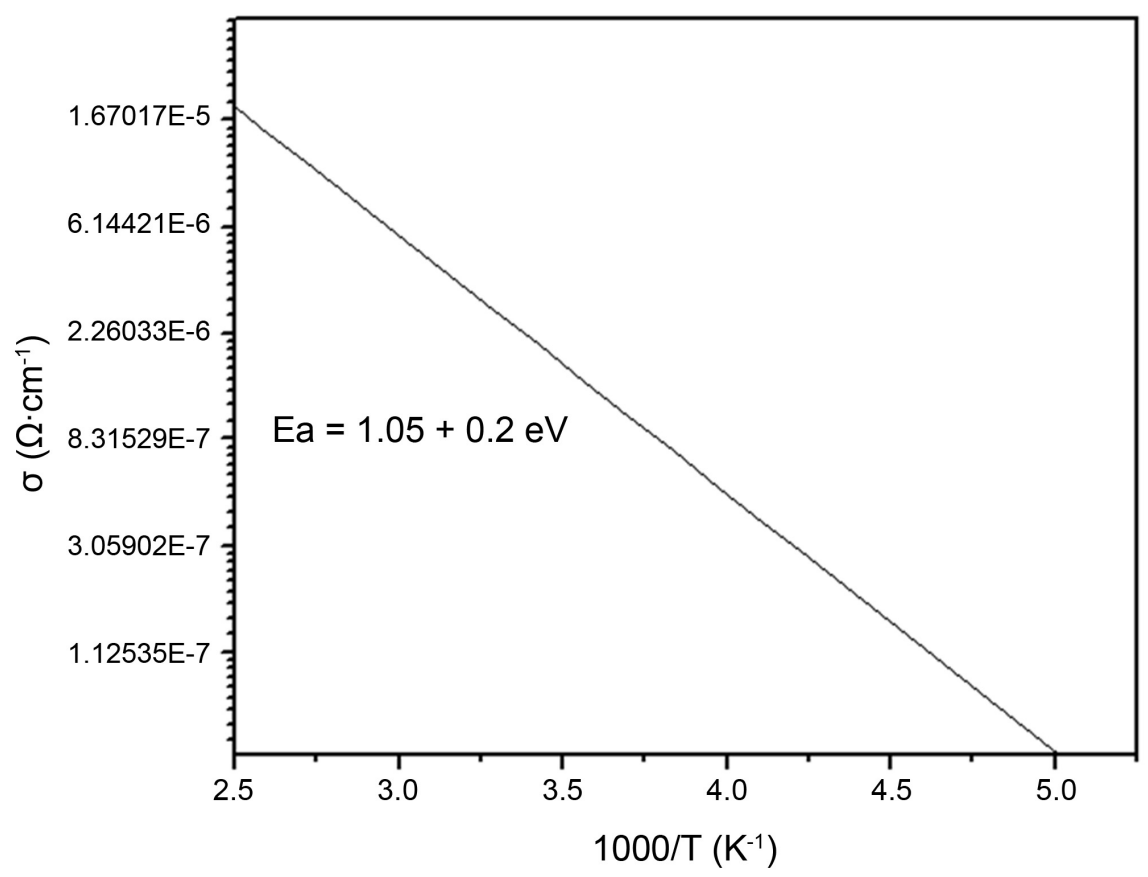

Figure 3. dc conductivity measurements of VOP/POMA/PEO.

To investigate the spectroelectrochemical behavior were recorded using UVvis spectra and were carried out at potentials determined from cyclic voltammograms (CVs) to fixed potential in redox state. The cyclic voltammograms were previously published by our group [7]

Based on the cyclic voltammograms [7], analysis of color transitions at the observed potential changes was carried out with spectroelectrochemical studies. The changes in the UV-vis absorbance spectra of VOP/PEO, VOP/POMA, and VOP/POMA/PEO films, deposited on glass/ITO, as a function of potential applied to the electrode, are shown in Figures 4-6, respectively. In VOP/PEO (Figure 4) a significant change in absorbance was observed when the potential of working electrode was swept from $-0.50 \mathrm{~V}$ to $1.0 \mathrm{~V}$. The absorption spectra display broad, intense bands in the visible region, between 280 and $420 \mathrm{~nm}$. This absorption is due to the reduction of the $\mathrm{V}^{\mathrm{V}}$ sites in the lattice to $\mathrm{V}^{\mathrm{IV}}$ during the electrochemical process, concomitant with the process of $\mathrm{Li}^{+}$insertion, which leads to the formation of $\mathrm{LiV}_{2} \mathrm{O}_{5}$ species [29] [30]. The electrochemical properties of VOP/PEO are similar to those of $\mathrm{V}_{2} \mathrm{O}_{5}$ obtained via the sol-gel process [22]. At a potential of $+1.0 \mathrm{~V}$, the material appears yellow, which can be attributed to the absorption characteristic of $\mathrm{V}^{\mathrm{V}}$. At a potential of $0.0 \mathrm{~V}$, the material appears green, which can be attributed to the absorption characteristic of $\mathrm{V}^{\mathrm{V} / \mathrm{IV}}$. Finally, at a potential of $+0.3 \mathrm{~V}$, the material appears blue, which can be attributed to the absorption characteristic of $\mathrm{V}^{\mathrm{IV}}$. PEO is a transparent material which does not influence the UV-vis spectrum during the electrochromic processes in VOP/PEO. As an important point, $\mathrm{V}_{2} \mathrm{O}_{5}$ has a yellow coloration and in the redox state associated with cathodic Li-insertion, the $\mathrm{Lix}_{2} \mathrm{O}_{5}$ specie formed is pale blue [31]. The electrochemical change in redox state causes an 


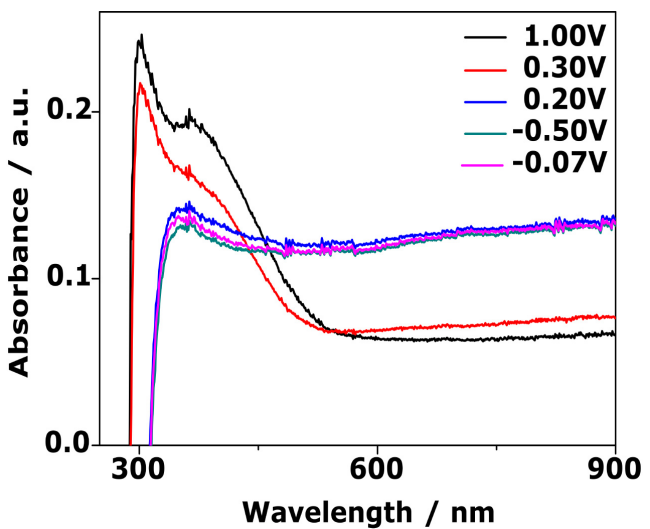

Figure 4. Spectroelectrochemical studies of VOP/PEO.

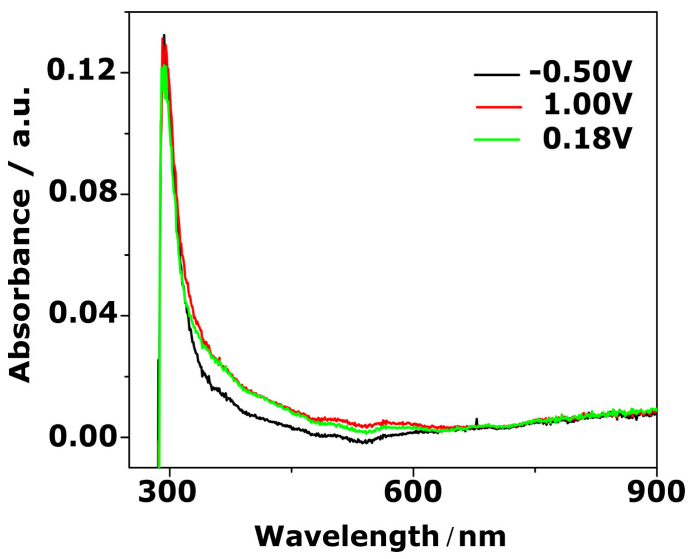

Figure 5. Spectroelectrochemical studies of VOP/POMA.

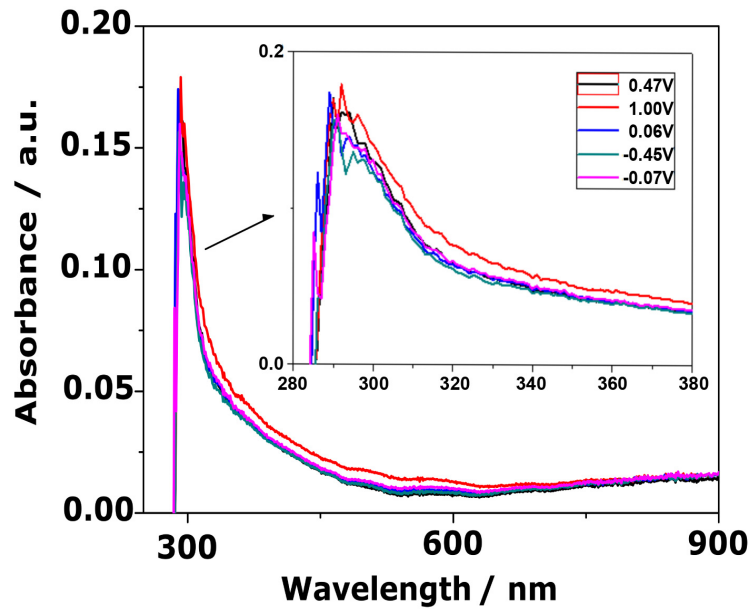

Figure 6. Spectroelectrochemical studies of VOP/POMA/PEO.

intense electronic absorption band due to optical intervalence charge transfer. The polymeric species, $\mathrm{PEO}$, is an ionic conductor and a colorless material at different potential values [2]. In Figure 5 and Figure 6 no significant change is observed in the absorption spectra over the potential range; a single band is observed at around $300 \mathrm{~nm}$. These results can be explained by the fact that the in 
the hybrid compound VOP/POMA, POMA contributes a pale-yellow color, and VOP contributes a blue color associated with the reduction process, resulting in a dark blue color overall. Additionally, in the oxidation process of VOP/POMA, POMA contributes a blue color and VOP contributes a pale yellow color, again resulting in a blue color. It is important to point out that there is a change of absorption for POMA at different potentials due to the different electrochemical doped and undoped states [32]. In its oxidized state, the color of the film is blue, resulting in a blue shift of the absorption peak. However, in its reduced state, the color of the film changes to light yellow [33]. Thus, in the spectroelectrochemical studies, the absorption behavior of the hybrid material VOP/POMA does not change significantly during the redox process. A similar result is observed in VOP/POMA/PEO (Figure 6) since PEO is a colorless polymer, and thus the colors of VOP and POMA are dominant.

Based on cyclic voltammograms previously published by our group [7] it was possible to identify the highest occupied molecular orbital of VOP/PEO, VOP/ POMA, and VOP/POMA/PEO. The onset oxidation potentials of these materials were observed to be $-0.07 \mathrm{~V}, 0.18 \mathrm{~V}$, and $0.07 \mathrm{~V}$ for VOP/PEO, VOP/POMA, and VOP/POMA/PEO, respectively. Furthermore, the HOMO positions were measured from the current onset of the first observed anodic signal. From the Equation (2), the HOMO of VOP/PEO, VOP/POMA, and VOP/ POMA/PEO are $-4.77,-4.84$, and $-4.74 \mathrm{eV}$, respectively.

From Figures 7-9 (Tauc plots), it was possible to measure the optical band gap and, consequently, to obtain the LUMO level. The optical band gap, LUMO, and HOMO values presented in Table 1 represent the combination of the cyclic voltammetric studies and the Tauc plot method.

As observed, VOP/PEO has a lower band gap compared to those of VOP/POMA and VOP/POMA/PEO. This value can be attributed to the greater electron injection process, higher available photon flux, and a greater number of electronic interactions involving electrons, photons, and phonons [34]. Furthermore, the lower band gap of VOP/PEO compared to those of VOP/POMA and VOP/ POMA/PEO can be inferred by the presence of structural defects, which promote an increase in localized states of density in the band gap, consequently decreasing the energy gap.

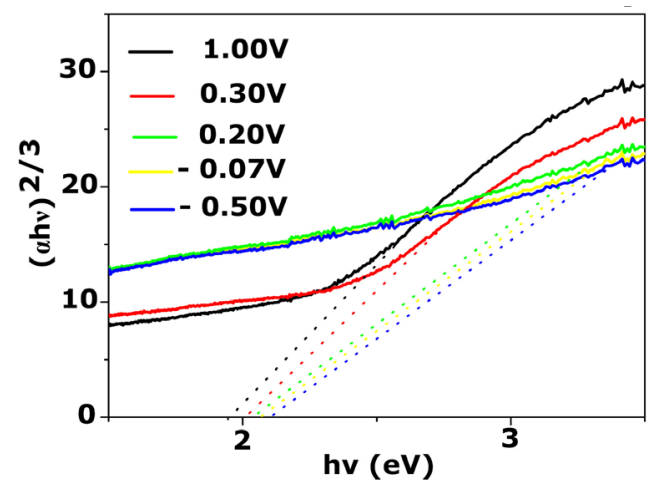

Figure 7. Plot of $(\alpha h v)^{2 / 3}$ vs $h v$ for VOP/PEO. 


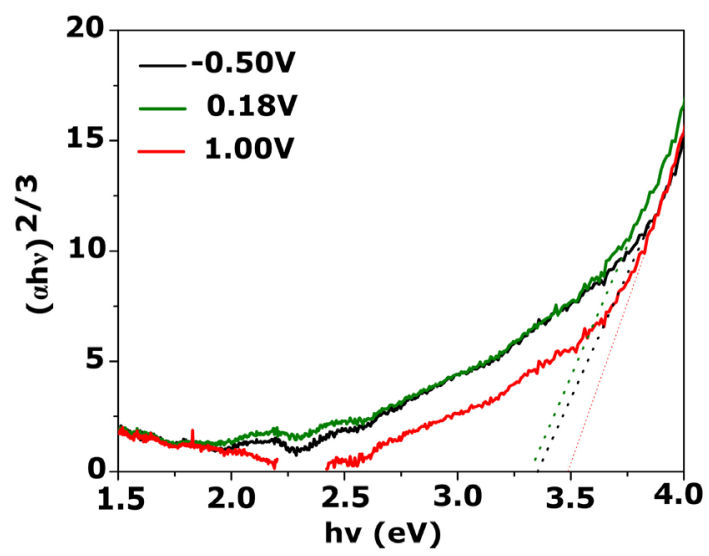

Figure 8. Plot of $(\alpha h v)^{2 / 3}$ vs $h v$ for VOP/POMA.

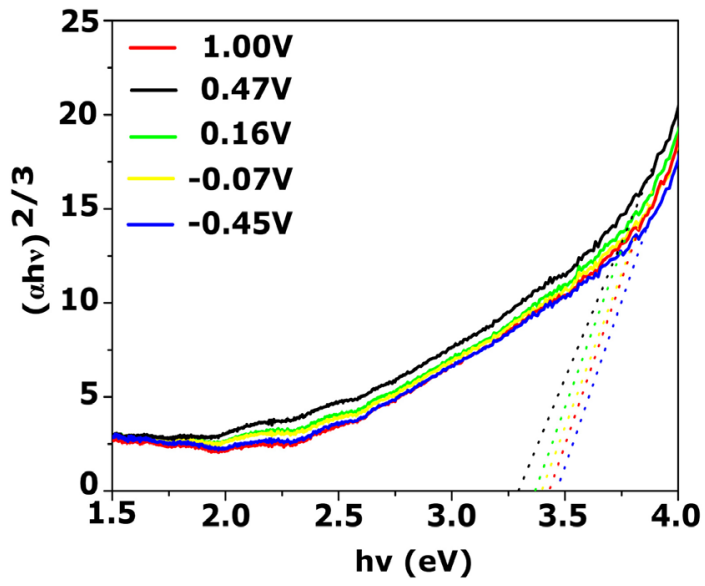

Figure 9. Plot of $(\alpha h v)^{2 / 3}$ vs $h v$ for VOP/POMA/PEO.

Table 1. The HOMO-LUMO energy levels and band gap energies of VOP/PEO, VOP/ POMA, and VOP/POMA/PEO.

\begin{tabular}{cccc}
\hline Hybrid Materials & $E_{\mathrm{HOMO}}$ from VC $(\mathrm{eV})$ & $E_{\mathrm{GAP}}$ from Tauc plot $(\mathrm{eV})$ & $E_{\mathrm{LUMO}}(\mathrm{eV})$ \\
\hline VOP/PEO & -4.77 & 2.65 & -2.12 \\
VOP/POMA & -4.84 & 3.30 & -1.54 \\
VOP/POMA/PEO & -4.74 & 3.40 & -1.34 \\
\hline
\end{tabular}

\section{Conclusion}

In this work, the intercalation of POMA and PEO into the porous $\mathrm{V}_{2} \mathrm{O}_{5}$ matrix was studied. Intercalation of the polymers into $\mathrm{V}_{2} \mathrm{O}_{5}$ affected conductivity. After the insertion of polymers into the porous matrix, the conductivity increased compared to that of pristine $\mathrm{V}_{2} \mathrm{O}_{5}$, previously observed in our group. During the spectroelectrochemical process, it was observed that PEO did not influence the absorption during the electrochromic process as it is a transparent material, and therefore, the color changes during the process were exclusively due to the VOP. However, the presence of POMA in the VOP caused a color overlay that meant that during the electrochromic analysis, the color change was not significant. As 
$\mathrm{PEO}$ is a transparent material, $\mathrm{VOP} / \mathrm{POMA} / \mathrm{PEO}$ displayed an electrochromic variation similar to that of VOP/POMA. The Tauc method of determining the band gap of materials was used and the values were found to be $2.65 \mathrm{eV}, 3.30 \mathrm{eV}$, and $3.40 \mathrm{eV}$ for VOP/PEO, VOP/POMA, and VOP/POMA/PEO, respectively. The frontier orbital energies indicate that these materials can be considered as candidates as photosensing components in solar cells.

\section{Acknowledgements}

The authors gratefully acknowledge the fellowship provided by CAPES, FAPESP, FAPEMIG, INEO, and CNPq, which are also acknowledged for financial support. Additionally, this work has been a collaboration research project with members of the Rede Mineira de Química (RQ-MG) supported by FAPEMIG (Project: CEX-RED-00010-14).

\section{Conflicts of Interest}

The authors declare no conflicts of interest regarding the publication of this paper.

\section{References}

[1] Gómez-Romero, P. and Gomez-Romero, B.P. (2001) Hybrid Organic-Inorganic Materials-In Search of Synergic Activity. Advanced Materials, 13, 163-174. https://doi.org/10.1002/1521-4095(200102)13:3<163::AID-ADMA163>3.0.CO;2-U

[2] Guerra, E.M., Ciuffi, K.J. and Oliveira, H.P. (2006) $\mathrm{V}_{2} \mathrm{O}_{5}$ Xerogel-Poly(ethylene oxide) Hybrid Material: Synthesis, Characterization, and Electrochemical Properties. Journal of Solid State Chemistry, 179, 3814-3823. https://doi.org/10.1016/j.jssc.2006.08.018

[3] Allcock, H.R. (1992) Rational Design and Synthesis of New Polymeric Material. Science, 255, 1106-1112. https://doi.org/10.1126/science.255.5048.1106

[4] Sanchez, C., Julián, B., Belleville, P. and Popall, M. (2005) Applications of Hybrid Organic-Inorganic Nanocomposites. Journal of Materials Chemistry, 15, 3559-3592. https://doi.org/10.1039/b509097k

[5] Judeinstein, P. and Sanchez, C. (1996) Hybrid Organic-Inorganic Materials: A Land of Multidisciplinarity. Journal of Materials Chemistry, 6, 511-525. https://doi.org/10.1039/JM9960600511

[6] Gomez-Romero, P. and Sanchez, C. (2004) Functional Hybrid Materials. Wiley-VCH, Hoboken.

[7] Guerra, E.M. and Oliveira, H.P. (2009) Synthesis and Characterization of Ternary Hybrid Material Based on Poly-o-methoxyaniline and Poly(ethylene oxide) in Mesostructured V2O5. Journal of Sol-Gel Science and Technology, 50, 103-110. https://doi.org/10.1007/s10971-009-1910-9

[8] Guerra, E.M., Cestarolli, D.T. and Oliveira, H.P. (2010) Effect of Mesoporosity of Vanadium Oxide Prepared by Sol-Gel Process as Cathodic Material Evaluated by Cyclability during $\mathrm{Li}^{+}$Insertion/Deinsertion. Journal of Sol-Gel Science and Technology, 54, 93-99. https://doi.org/10.1007/s10971-010-2162-4

[9] Novak, B.M. (1993) Hybrid Nanocomposite Materials between Inorganic Glasses and Organic Polymers. Advanced Materials, 5, 422-433. 
https://doi.org/10.1002/adma.19930050603

[10] Loy, D.A. and Shea, K.J. (1995) Bridged Polysilsesquioxanes. Highly Porous Hybrid Organic-Inorganic. Chemical Reviews, 95, 1431-1442. https://doi.org/10.1021/cr00037a013

[11] Sharp, K.G. (1998) Inorganic/Organic Hybrid Materials. Advanced Materials, 10, $1243-1248$.

https://doi.org/10.1002/(SICI)1521-4095(199810)10:15<1243::AID-ADMA1243>3.0 .CO;2-6

[12] Sanchez, C., Ribot, F. and Lebeau, B. (1999) Molecular Design of Hybrid Organic-Inorganic Nanocomposites Synthesized via Sol-Gel Chemistry. Journal of Materials Chemistry, 9, 35-44. https://doi.org/10.1039/a805538f

[13] Brinker, C.J. and Scherer, G. (1990) Sol-Gel Science. In: Sol-Gel Science-The Physics and Chemistry of Sol-Gel Processing, Academic Press, Boston.

[14] Diniz, M.O., Golin, A.F., Santos, M.C., et al. (2019) Improving Performance of Polymer-Based Ammonia Gas Sensor Using POMA/V2O5 Hybrid Films. Organic Electronics, 67, 215-221. https://doi.org/10.1016/j.orgel.2019.01.039

[15] Santos, M.C., Hamdan, O.H.C., Valverde, S.A., et al. (2019) Synthesis and Characterization of V2O5/PANI Thin Films for Application in Amperometric Ammonia Gas Sensors. Organic Electronics, 65, 116-120. https://doi.org/10.1016/j.orgel.2018.11.013

[16] Kanatzidis, M.G., Wu, C.G., Marcy, H.O. and Kannewurf, C.R. (1989) Conductive-Polymer Bronzes. Intercalated Polyaniline in Vanadium Oxide Xerogels. Journal of the American Chemical Society, 111, 4139-4141. https://doi.org/10.1021/ja00193a078

[17] Wu, C.-G., DeGroot, D.C., Marcy, H.O., et al. (1996) Redox Intercalative Polymerization of Aniline in V2O5 Xerogel. The Postintercalative Intralamellar Polymer Growth in Polyaniline/Metal Oxide Nanocomposites Is Facilitated by Molecular Oxygen. Chemistry of Materials, 88, 1992-2004. https://doi.org/10.1021/cm9600236

[18] Kundu, S., Satpati, B., Mukherjee, M., et al. (2017) Hydrothermal Synthesis of Polyaniline Intercalated Vanadium Oxide Xerogel Hybrid Nanocomposites: Effective Control of Morphology and Structural Characterization. New Journal of Chemistry, 41, 3634-3645. https://doi.org/10.1039/C7NJ00372B

[19] Posudievsky, O.Y., Biskulova, S.A. and Pokhodenko, V.D. (2004) New Hybrid Guest-Host Nanocomposites Based on Polyaniline, Poly(ethylene oxide) and V2O5. Journal of Materials Chemistry, 14, 1419-1423. https://doi.org/10.1039/B400495G

[20] Arıcan, D., Aktaş, A., Kantekin, H. and Koca, A. (2014) Electrochromism of Electropolymerized Cobaltphthalocyanine-Quinoline Hybrid. Solar Energy Materials \& Solar Cells, 132, 289-295. https://doi.org/10.1016/j.solmat.2014.08.026

[21] Garreau, A. and Duvail, J.-L. (2014) Recent Advances in Optically Active Polymer-Based Nanowires and Nanotubes. Advanced Optical Materials, 2, 1122-1140. https://doi.org/10.1002/adom.201400232

[22] Oliveira, H.P., Graeff, C.F.O., Brunello, C.A. and Guerra, E.M. (2000) Electrochromic and Conductivity Properties: A Comparative Study between Melanin-Like/ $\mathrm{V}_{2} \mathrm{O}_{5} \cdot \mathrm{nH}_{2} \mathrm{O}$ and Polyaniline/V2O5 $\cdot \mathrm{nH}_{2} \mathrm{O}$ Hybrid Materials. Journal of Non-Crystalline Solids, 273, 193-197. https://doi.org/10.1016/S0022-3093(00)00129-0

[23] Gale, R.J. (1988) Spectroelectrochemistry: Theory and Practice. Springer US, Berlin. https://doi.org/10.1007/978-1-4613-0985-7

[24] Coulter, J.B. and Birnie, D.P. (2018) Assessing Tauc Plot Slope Quantification: ZnO 
Thin Films as a Model System. Physica Status Solidi (B): Basic Research, 255, Article ID: 1700393. https://doi.org/10.1002/pssb.201700393

[25] Ramana, C.V., Hussain, O.M., Uthanna, S. and Srinivasulu Naidu, B. (1998) Influence of Oxygen Partial Pressure on the Optical Properties of Electron Beam Evaporated Vanadium Pentoxide Thin Films. Optical Materials, 10, 101-107. https://doi.org/10.1016/S0925-3467(97)00168-7

[26] Tritschler, U., Zlotnikov, I., Zaslansky, P., et al. (2014) Hierarchically Structured Vanadium Pentoxide-Polymer Hybrid Materials. ACS Nano, 8, 5089-5104. https://doi.org/10.1021/nn501153u

[27] Tauc, J. (1969) Optical Properties and Electronic Structure of Amorphous Semiconductors. In: Optical Properties of Solids, Springer US, Boston, 123-136. https://doi.org/10.1007/978-1-4757-1123-3_5

[28] Zajac, G.W., Gallas, J.M., Cheng, J., et al. (1994) The Fundamental Unit of Synthetic Melanin: A Verification by Tunneling Microscopy of X-Ray Scattering Results. Biochimica et Biophysica Acta: General Subjects, 1199, 271-278. https://doi.org/10.1016/0304-4165(94)90006-X

[29] Talledo, A. and Granqvist, C.G. (1995) Electrochromic Vanadium-Pentoxide-Based Films: Structural, Electrochemical, and Optical Properties. Journal of Applied Physics, 77, 4655-4666. https://doi.org/10.1063/1.359433

[30] Thi Be Bay, N., Minh Tien, P., Badilescu, S., et al. (1996) Optical and Electrochemical Properties of Vanadium Pentoxide Gel Thin Films. Journal of Applied Physics, 80, 4655-43507. https://doi.org/10.1063/1.2844438

[31] Mortimer, R.J. (1997) Electrochromic Materials. Chemical Society Reviews, 26, 147-156. https://doi.org/10.1039/cs9972600147

[32] Guerra, E.M., Brunello, C.A., Graeff, C.F.O. and Oliveira, H.P. (2002) Synthesis, Characterization, and Conductivity Studies of Poly-o-Methoxyaniline Intercalated into V2O5 Xerogel. Journal of Solid State Chemistry, 168, 134-139. https://doi.org/10.1006/jssc.2002.9700

[33] Tu, L., Jia, C., Weng, X. and Deng, L. (2011) Study on Poly-O-Anisidine Film with the Properties of Electrochromism and Infrared Emissivity Modulation. Synthetic Metals, 161, 2045-2048. https://doi.org/10.1016/j.synthmet.2011.06.032

[34] Prima, E.C., Al Qibtiya, M., Yuliarto, B., et al. (2016) Influence of Anthocyanin Co-Pigment on Electron Transport and Performance in Black Rice Dye-Sensitized Solar Cell. Ionics (Kiel), 22, 1687-1697. https://doi.org/10.1007/s11581-016-1673-6 